This PDF is a selection from an out-of-print volume from the National Bureau of Economic Research

Volume Title: The Rate and Direction of Inventive Activity: Economic and Social Factors

Volume Author/Editor: Universities-National Bureau Committee for Economic Research, Committee on Economic Growth of the Social Science Research Council

Volume Publisher: Princeton University Press

Volume ISBN: 0-87014-304-2

Volume URL: http://www.nber.org/books/univ62-1

Publication Date: 1962

Chapter Title: Locational Differences in Inventive Effort and Their Determinants

Chapter Author: Wilbur R. Thompson

Chapter URL: http://www.nber.org/chapters/c2120

Chapter pages in book: (p. 253 - 272) 


\title{
Locational Differences in Inventive Effort and Their Determinants
}

\author{
WILBUR R. THOMPSON \\ WAYNE STATE UNIVERSITY
}

THIS is an empirical study with selected patent grants as the measure of inventive activity. The logic of an empirical approach here might be set forth as follows: lacking a ready-made stock of directly relevant conceptual work on which to draw and build, and lacking a longstanding familiarity with the general literature on the economics of technology on which pioneering deduction could be based, I selected the pedestrian task of assembling and editing some rough measures of the locational pattern of inventive activity. The job seemed to need doing; they also serve who only stack and weight.

While this rationale embodies the spirit of the effort, a more chronologically accurate description of the origin of this paper is that for some time now I have had in hand the grist to be milled. Specifically, an earlier piece of work left me in possession of a large number of worksheets on which were recorded the residences of persons who had received patent grants (primarily) during the years 1947 and 1948, tabulated by selected patent classes. ${ }^{1}$ It would have been criminal, it seemed, to let that data gather dust when with-what seemed at the time-only minor marginal costs the data could be rearranged to shed light on some of the questions at issue in this Conference. Naturally, the additional investment mounted and the light generated was not quite so bright as had been hoped.

\section{Identification of the Inventing Population}

A sensible way to begin a locational analysis of invention would be to attempt to identify "inventors"- at least in broad terms. What population group best characterizes those who invent: male adults or the

\footnotetext{
${ }^{1}$ See Wilbur R. Thompson and John M. Mattila, An Econometric Model of Postwar State Industrial Development, Detroit, Wayne State University Press, 1959. The reason why the data on patent grants dates back to the 1947-48 period is that the econometric model was essentially a compilation of equations for estimating the growth of manufacturing employment, by industry, for the period 1947-54. Patent grants were, therefore, incorporated into the work as a leading series, applying to the origin year of the growth period. Ordinarily, the fact that the data is a decade old would not be too disturbing, but 1947-48 patent grants relate to patent applications of about three years earlier and this places the more critical date in the latter part of the war. I cannot say with assurance that this does or does not affect, significantly, my conclusions.
} 
college bred or city dwellers or the professionally trained or craftsmen? Nine separate populations were defined-lifted from the Census of Population would be more accurate-and the number of persons in each state in each of these groups (1950) was correlated with the average annual number of patent grants issued to residents of that state (1952-54). ${ }^{2}$ The simple, linear coefficients of correlation are presented in Table 1.

TABLE 1

Coffficients of Correlation of Average Annual Number of Patents IsSUEd to State Residents, 1952-54, WrTh Various

Population Classes, by States, $1950^{\circ}$

\begin{tabular}{|c|c|c|}
\hline Population Group & Coefficient & $\begin{array}{l}\text { Per Cent } \\
\text { Explained } \\
\text { Variance }\end{array}$ \\
\hline Number of persons 21 years old and over & .930 & 86.5 \\
\hline $\begin{array}{l}\text { Number of persons } 25 \text { years old and over who have com- } \\
\text { pleted } 4 \text { or more years of college }\end{array}$ & .937 & 87.8 \\
\hline $\begin{array}{l}\text { Number of persons residing in the urbanized part of a } \\
\text { standard metropolitan area }\end{array}$ & .964 & 92.9 \\
\hline Number of professional, technical, and kindred workers & .952 & 90.6 \\
\hline Number of craftsmen, foremen, and kindred workers & .950 & 90.2 \\
\hline $\begin{array}{l}\text { Number of professional, technical, and kindred workers } \\
\text { plus craftsmen, foremen, and kindred workers }\end{array}$ & .955 & 91.2 \\
\hline $\begin{array}{l}\text { Number of chemists, designers, draftsmen, engineers, } \\
\text { natural scientists, and testing technicians }{ }^{b}\end{array}$ & .981 & 96.2 \\
\hline Total manufacturing employment & .928 & 86.1 \\
\hline Total labor force & .940 & 88.4 \\
\hline
\end{tabular}

Source: Derived from 1950 Census of Population, Vol. II, Parts 1-49 and Statistical Abstract of the United States, 1955, Table 604, p. 500.

"The years 1952-54 for patent grants were used with 1950 population data because the typical (median) time lag between a patent application and a patent grant is about three years.

${ }^{b}$ An indication of the relative weights of these six occupational classes in the experienced civilian labor force can be gained by comparing their U.S. totals in thousands: chemists, 75.7; designers, 40.1 ; draftsmen, 124.7 ; engineers, 534.4 ; natural scientists, 40.7; and testing technicians, 77.0.

${ }^{2}$ The choice of the year 1950 with which to date the population characteristics was, of course, dictated by the availability of data from the Decennial Census; the choice of a later period, 1952-54, for the index of invention reflects the fact that (on the basis of a rough guess from a small sample) the typical (median) lag between the application for and receipt of a patent grant is about three years. The correlation is, then, chronologically synchronized on the year 1950. 
With a simple correlation coefficient of 0.93 , the distribution of adult population among the states accounts for over 86 per cent $\left(0.93^{2}\right)$ of the interstate variation in the number of patent grants. Against this benchmark of inventors as "just folks," we can assess the relevance of more refined expressions of the inventing population. Some of the more interesting inferences that may be drawn from Table 1 are:

1. Substitution of either the labor force (0.94) or manufacturing employment (0.93) for the adult population does not raise the correlation coefficient.

2. Recourse to a very select population group, the college-educated (0.94), accomplishes no notable improvement in the statistical fit.

3. A significant improvement in the correlation does occur when the "urbanized population" is correlated with patents $(0.96)$; explained variance increases from 86 to 93 per cent.

4. The best association is achieved by breaking through the professional and skilled worker occupational aggregates (the two correlations are on a par at 0.95 ) to the narrower amalgam of six selected occupational classes: chemists, designers, draftsmen, engineers, natural scientists and testing technicians (0.98). With this occupational mix, explained variance reaches a peak of 96 per cent.

If the charge be leveled that the most distilled product, 4, above, has become the bland correlation of invention with inventors, the defense is that this exercise was designed to name the population class from which inventors arise and not to quantify the inventing function. Thus, the early returns suggest that an identifiable occupational class of "inventors" does exist and can be roughly described. And that the next best characterization of the inventor is that of city-dweller. ${ }^{3}$ So, while we may have but linked invention with inventors and not yet placed the latter in space, we have at least come to know better those whom we seek. (Although, admittedly, 4 might be merely an index of the inventive culture.)

An aggregate of all patents, when compared to the alternatives, is not without virtue in the difficult business of assessing the locational pattern of inventive activity, but this gross conglomerate will now be abandoned in favor of narrower and more internally homogeneous

\footnotetext{
${ }^{3}$ However, the inter-correlation between the number of persons in the six selected occupations and "urbanized-area" population is so high (.98) that the combination of these two factors (or any other two) in multiple correlation does not appreciably raise the level of explained variance.
} 
classes of patents. The shoal on which the all-patent index runs aground is the familiar one of "industry-mix." The frequency with which patents are granted varies greatly between the many patent classes. Every new variation of a chemical compound becomes a potential patent grant; patent grants in the class "chemistry, carbon compounds" ran along at the rate of about 25 per week in 1947, as against a weekly rate of about 4 in "internal combustion engines" and less than one per week in "metallurgy."

An appreciation of the large variations in patent frequencies between classes quickly dispels any mystery that might be generated by the revelation that Delaware residents have received more patents per capita than the inhabitants of any other state in every year from 1936 to 1954 , the full period for which data has been tabulated and presented in the Statistical Abstract. ${ }^{4}$ Moreover, New Jersey, another chemical-industry state, took second place honors three-quarters of the time during this 19 -year period. Thus, if the research orientation of a state reflects its industrial structure, any index which purports to measure the inventiveness of the residents of a state must be deflated for the industry-mix of that state.

The construction of a satisfactory overall state index of inventiveness was not stymied by lack of applicable index number technique, but rather by lack of appropriate data. Unfortunately, the Patent Office does not report the distribution of patent grants by states for the various patent classes, and without this information we can not even begin to construct a comprehensive set of "patent relatives." (What constitutes a "high" or "low" rate of patenting in engines? in plastics?) What is more important, our way is barred by the heroic task of linking patent classes to Census-defined industry groups, a clear prerequisite to the derivative job of compiling a set of industry weights to apply to the patent relatives. The industry weights would, of course, match the industry-mix of the local economy. The dilemma to be resolved is that patents are classified by process and industries by product, and processes often criss-cross product lines in bewildering fashion. "Abrading" (patent class number 51) includes technical advances in grinding wheels (a subgroup of the stone, clay and glass industry group) and drill presses (nonelectrical machinery) and certainly is related to fabricated metal products and (optical) instrument manufacturing. "Chemistry, electrical and wave energy" (patent class number 204) includes electrolysis (chemicals and allied industries)

${ }^{4}$ Derived from the 1946 issue, Table 986, p. 880 and the 1955 issue, Table 604, p. 506. 
and electroplating (fabricated metal products). The task of aligning patent class with industry group is a formidable one and deserves a more skilled and sustained effort than can be rendered here and now, although some tentative probings will be attempted below.

\section{Inventors as City Dwellers}

The first tentative conclusion offered was that inventive activity is more a matter of occupation than of residence, but the correlation between the number of persons residing in "urbanized areas" of a state and the number of patents going to that state was much too close to deny the urge to investigate a bit further. Surely, we would all guess that inventing is more a pursuit of city than of town or rural inhabitants and that the Census standard metropolitan areas would encompass substantially more than their pro rata share of inventors. We might make this guess with some vague feeling of uneasiness, probably traceable to our heritage (mythology?) of Connecticut Yankees and basement workshops, but the image of the Du Pont laboratories would surely prevail. For all the merit of intuition and deduction, however, some rough quantification of the "urban-ness" of invention would help fix this impression and set the stage for more certain and sophisticated conceptualizing.

Our approximation of the urban-ness of invention is derived from data prepared for an earlier study, alluded to above. Lists of the places of residence of patentees were drawn from chronological entries in the weekly Official Gazette of the Patent Office and grouped by patent class (Class 123, internal-combustion engines, Class 18, plastics, for example). A dichotomy of patentees' residences was set up: metropolitan area residents and nonmetropolitan area residents, with the latter group classified by distance of residence from the central business district of the central city of the nearest standard metropolitan area - that is to say, by how far removed these places are from (industrial) "civilization." (The metropolitan area residents were, of course, tabulated by area and this data will become the focus of our inquiry below.)

The pattern of Table 2 is clear : the approximately one-half ( $54.6 \mathrm{per}$ cent) of the total U.S. population residing in (168) standard metropolitan areas in 1945 received over four-fifths of the patents granted in the years 1947 and 1948 in fourteen out of sixteen of the selected processes associated with the metal, machinery, vehicle, and chemical industries. Ignoring the widest variations (particularly characteristic 
TABLE 2

Distribution of Patent Grants Between Metropolitan and Nonmetropolitan Areas for Selected Patent Classes, 1947-48

\begin{tabular}{|c|c|c|c|c|c|}
\hline \multirow{2}{*}{\multicolumn{2}{|c|}{ PATENT CLASS }} & \multicolumn{4}{|c|}{ PATENTS GRANTED (1947-48) TO RESIDENTS OF : } \\
\hline & & \multicolumn{2}{|c|}{$\begin{array}{c}\text { Standard Metropolitan } \\
\text { Areas }\end{array}$} & \multicolumn{2}{|c|}{ Other Areas } \\
\hline Numb & Title & Number & Per Cent & Number & Per Cent \\
\hline 123 & Internal-combustion engines & 312 & 81.2 & 72 & 18.8 \\
\hline 75 & Metallurgy & 106 & 80.9 & 25 & 19.1 \\
\hline 266 & Metallurgical apparatus & 62 & 80.5 & 15 & 19.5 \\
\hline 78 & Metal forging and welding & 33 & 78.6 & 9 & 21.4 \\
\hline 148 & Metal treatment & 72 & 92.3 & 6 & 7.7 \\
\hline 80 & Metal rolling & 11 & 84.6 & 2 & 15.4 \\
\hline 205 & Metal drawing & 5 & 83.3 & 1 & 16.7 \\
\hline \multirow[t]{2}{*}{22} & Metal founding & 96 & 89.7 & 11 & 10.3 \\
\hline & Total of 7 basic metal processes & es 385 & 84.6 & 70 & 15.4 \\
\hline 29 & Metal working & 282 & 86.0 & 46 & 14.0 \\
\hline 82 & Turning & 42 & 75.0 & 14 & 25.0 \\
\hline \multirow[t]{2}{*}{90} & Gear cutting, milling, and planing & 98 & 83.8 & 19 & 16.2 \\
\hline & Total of 2 machining processes & 140 & 80.9 & 33 & 19.1 \\
\hline 51 & Abrading $^{a}$ & 216 & 83.4 & 43 & 16.6 \\
\hline 23 & Chemistry $^{a}$ & 184 & 84.4 & 34 & 15.6 \\
\hline 260 & Chemistry, carbon compounds ${ }^{b}$ & 309 & 87.0 & 46 & 13.0 \\
\hline 18 & Plastics & 393 & 85.2 & 68 & 14.8 \\
\hline \multirow{3}{*}{204} & $\begin{array}{l}\text { Chemistry, electrical and wave } \\
\text { energy }^{a}\end{array}$ & 96 & 93.2 & 7 & 6.8 \\
\hline & Total of 4 chemistry processes & 982 & 86.4 & 155 & 13.6 \\
\hline & $\begin{array}{l}\text { Total of } 16 \text { selected patent } \\
\text { classes }\end{array}$ & 2,317 & 84.7 & 419 & 25.3 \\
\hline
\end{tabular}

SourCe: Derived from Official Gazette of the Patent Office, Dept. of Commerce, Weekly issues 1947-48.

${ }^{a}$ Data is for one year only, 1947.

${ }^{b}$ Figures are for a twelve week sample from the year 1947. Patent grants in this class were so numerous that data was tabulated for only the first week of each month.

of the smaller-frequency patent classes wherein the sample was too small to be a reliable index), the proportion of patent grants issued to metropolitan area residents is remarkably similar for the chemistry, basic metal, and metal working processes, 86.4, 84.6, and 86.0 per cent, respectively. Patents covering machining operations and internal- 
combustion engines stand close by at 80.9 and 81.2 per cent, respectively. Abrading, a patent class built on a process which cuts across most of the product lines (industries) associated with the other patent classes, and more besides (instruments and stone, clay and glass, for example), lies, appropriately, between these two groups with 83.4 per cent of its patentees residents of metropolitan areas.

By introducing a little judgment and pressing inference a bit harder, an even closer approximation to the urban-ness of invention can, I think, be sensibly made. The standard metropolitan areas, for reasons of efficacy in data collection, are delineated along county lines and their central cities often lie well off-center in their counties, causing the influence of the city to spill over county lines, asymmetrically. Clearly, persons may live across a county line but still be within easy commuting radius of a central city. If we add, therefore, to the 2,317 patents granted to metropolitan area residents, the 116 granted to persons who lived outside of these metropolitan areas but less than twenty-five miles from the center of the central city of the nearest metropolitan area, then the metro-nonmetro division of all patents classified in Table 2 becomes 2,433 to 303. (A less than twenty-fivemile commuting radius would seem to be reasonable, especially in view of the fact that many industrial firms are located on the periphery of central cities.) The best estimate is now this: the approximately 57 per cent of the population who resided in standard metropolitan areas (in 1945) or within twenty-five miles of the central city of such an area ${ }^{5}$ received (in 1947-48) approximately 90 per cent of the patents granted in sixteen selected patent classes covering chemistry, metal, machinery and engine products and processes.

\section{Invention as a By-Product of Employment}

The derivation of a measure of the urban-ness of invention was but a by-product of the process of classifying the patents by region, preparatory to a comparative analysis of inventive activity at the metropolitan area level. Closer analysis of the patent data might have been pursued at the state level of areal subdivision, as was done in the earlier

${ }^{5}$ The estimate of population residing outside of standard metropolitan areas but within twenty-five miles of the center of a central city of such an area was derived by multiplying the total population of all standard metropolitan areas by the ratio of the number of patents received by these persons to the number received by the metropolitan area residents. $(116 / 2,317=.05)$. That is, the assumption was made that the number of patent grants per capita was the same inside and immediately outside of the metropolitan area and, by implication, that the central city and suburban populations have the same relevant characteristics. 
study. But to stand pat at the state level has a number of disadvantages: (1) Since there are barely a dozen states which have industrialized to the stage where inventive activity in manufacturing is significant and measurable, the statistical analyst is forced to work with a very small sample; (2) a state is usually composed of a number of separate, usually diverse subeconomies (the specialized steel making Pittsburgh economy and the highly diversified Philadelphia economy and other Pennsylvania regions are rolled out into one statewide economic conglomerate); and (3) the city region (standard metropolitan area) is roughly coincident with the local labor market and is the maximum radius within which personal contacts can be conveniently maintained. Thus, the city region would seem to represent, in rough measure, the community of intellectual intercourse; industrial and cultural, vocational and avocational. The manipulation above of the all-patents data has, moreover, established the city as the hothouse of technology. Accordingly, the remainder of the paper will focus on the metropolitan community.

The first hypothesis to be tested with patent grant data, spatially distributed by standard metropolitan area of the patentees' residence, is that inventive activity (as measured by patents) of a given kind is highly correlated (positively) with the current regional distribution of employment in the industry (or industries) most closely associated with that kind of inventive activity. Specifically, we assume that the number of patent grants covering "turning and gear cutting" is determined by the number employed in the Census major industry group, machinery, except electrical, region by region. The proposition that the production centers of an industry are also its research centers seems plausible, at least on first blush. The reasoning here is that new products and techniques are largely spawned by persons who work for or are otherwise closely associated with the industry most closely linked with the particular idea or device: To the extent that this is so, a substantial, persistent, and even cumulative advantage would accrue to any region which gained a head start in a particular industry; perhaps technological differentials tend to widen-the rich to grow richer.

The hypothesis that invention is an avocation related to one's vocation in kind will be tested by simple linear correlations between the (absolute) number of patent grants and related employment (all employees, rather than production workers), for a number of industry groups. But the act of correlating the two variables in absolute terms 
leads to an inherent and strong inclination toward positive correlation. A size-with-size bias occurs because, even if patents and related employment were randomly distributed throughout the population, the population is not evenly distributed, spatially, throughout the country. Consequently, the New York-Northeastern New Jersey metropolitan area residents will normally possess more of almost every kind of patent grant and employment than will the residents of the Indianapolis metropolitan area, effecting thereby this inherent tendency toward positive correlation. We might try to hurdle this obstacle by jumping to something like patents per capita as an index, but why population as a deflator? What evidence do we have to support population as the relevant potential-inventor group? Nothing from the work above. Besides our purpose should be to discover the functional relationship between the potential-inventor group and the rate of patenting, and a deflating ratio would tend to obscure this relationship if it is curvilinear-that is, if there are economies of diseconomies of scale.

The technique adopted to separate the associated-employment effect from the population effect is a simple one, as befits the exploratory character of this study. Patent grants in a given patent class will be correlated with employment in a specific (the associated) industry, all manufacturing industry and total population. The latter two measures will provide norms with which the associated-employment correlations may be compared, bench marks well above sea level from which we may measure the altitude of the associated-employment coefficients.

The coefficients of correlation linking selected patent grants with employment in the associated industries for the seventy-four standard metropolitan areas for which employment data are available are presented in Table 3. The pattern, if one exists, is not a simple one or, if it is simple, our data or devices have not captured it. We can begin well. The hypothesis that the employees of an industry-and their neighbors-are the population from which the inventors of products and processes related to that industry are drawn is firmly supported by the internal combustion engine-transportation equipment industry correlations. Related employment exhibits a correlation coefficient of 0.90 , well above the coefficients for all manufacturing employment $(0.61)$ or total population $(0.55)$. With an "explained variance" of 81 per cent $\left(0.90^{2}\right)$, the evidence is impressive that automobile, aircraft, and shipbuilders are the principal contributors to engine technology. 
TABLE 3

Coefficients of Correlation of Patent Grants in Selected Patent Classes with Employment in Associated Industries, All Manufacturing Employment and Total Population, by Standard Metropolitan Areas, 1947

\begin{tabular}{|c|c|c|c|c|}
\hline \multirow[b]{3}{*}{ PATENT Class } & \multirow[b]{3}{*}{$\begin{array}{l}\text { ASSOCIATED CENSUS MAJOR } \\
\text { INDUSTRY GROUP }\end{array}$} & \multicolumn{3}{|c|}{$\begin{array}{l}\text { COEFFICIENTS OF CORRE- } \\
\text { LATION OF PATENTS WITH: }\end{array}$} \\
\hline & & \multicolumn{2}{|c|}{ Employment in: } & \multirow{2}{*}{$\begin{array}{l}\text { Total } \\
\text { Popu- } \\
\text { lation }\end{array}$} \\
\hline & & $\begin{array}{l}\text { Assoc. } \\
\text { Indus. }\end{array}$ & $\begin{array}{l}\text { All } \\
\text { Mfg. }\end{array}$ & \\
\hline Internal-combustion engines & Transportation equipment & .90 & .61 & .55 \\
\hline $\begin{array}{l}\text { Metallurgy; metallurgical } \\
\text { apparatus; metal forging } \\
\text { and welding; metal treat- } \\
\text { ment; metal rolling; metal } \\
\text { drawing; and metal founding }\end{array}$ & Primary metal industries & .64 & .94 & .92 \\
\hline Metal working & Fabricated metal products & .85 & .86 & .83 \\
\hline $\begin{array}{l}\text { Turning; Gear cutting, } \\
\text { milling and planing }\end{array}$ & Machinery, exc. electrical & .80 & .74 & .68 \\
\hline $\begin{array}{l}\text { Aggregate of the } 10 \text { metal- } \\
\text { making, working and } \\
\text { machining processes } \\
\text { (metallurgy through gear } \\
\text { cutting) in the three pre- } \\
\text { ceding groups }\end{array}$ & $\begin{array}{l}\text { Aggregate of: } \\
\text { Primary metal industries } \\
\text { Fabricated metal products } \\
\text { Machinery, exc. electrical }\end{array}$ & .83 & .93 & .89 \\
\hline Chemistry $^{a}$ & Chemicals and allied ind. & .95 & .92 & .94 \\
\hline $\begin{array}{l}\text { Chemistry, carbon } \\
\text { compounds }^{b}\end{array}$ & $\begin{array}{l}\text { Chemicals and allied prod. } \\
\text { Chemical plus Petroleum } \\
\text { and coal products }\end{array}$ & $\begin{array}{l}.94 \\
.95\end{array}$ & .92 & .92 \\
\hline Plastics & $\begin{array}{l}\text { Chemicals and allied prod. } \\
\text { Chemicals plus Rubber prod. }\end{array}$ & $\begin{array}{l}.91 \\
.95\end{array}$ & .90 & .92 \\
\hline
\end{tabular}

SourCe: Derived from Official Gazette of the Patent Office, Dept. of Commerce, weekly issues 1947-48 and Census of Manufactures, 1947 and 1954.

${ }^{a}$ Data is for one year only, 1947.

${ }^{b}$ Figures are for a twelve week sample from the year 1947. Patent grants in this class were so numerous that data was tabulated for only the first week of each month.

But the primary metal production centers do not seem to be the source of the patents covering the basic metal processes to anywhere near the same degree. In fact, employment in the primary metal industries statistically explains only about 41 per cent $\left(0.64^{2}\right)$ of the technically related patent grants, while population displays an 85 per cent association and total manufacturing employment reaches explained variance of 88 per cent. Why metalmaking, metal treating, 
and founding technology should be less indigenous to its production centers than engine technology is not readily apparent-to this layman. Are the skills less esoteric or has the linking of patent class to industry group been inept? Or is it simply that progress in primary metal technology originates in the shop of the metal user more often than in the workplace of the metalmaker?

There is little to choose from as between population, all manufacturing employment and employment in fabricated metal products in the attempt to account for metropolitan area variations in metal working patent grants, with explained variance clustered around 69 to 74 per cent. The principal explanation for the close correspondence of the three coefficients is that fabricated metals is perhaps the most ubiquitous manufacturing industry and employment in it is, therefore, highly correlated with both total manufacturing employment $(0.93)$ and even population ( 0.86$)$. (This may be compared with corresponding correlation coefficients of between 0.47 and 0.56 for the more spatially concentrated production of primary metals and transportation equipment.) Our statistical technique fails us here; we cannot isolate the specific from the general population.

But the nonelectrical machinery industry group comes to the rescue of our hypothesis; an aggregate of turning and gear cutting patents displays correlations which rise from a bench mark of 46 per cent explained variance for population, through 55 per cent for all manufacturing employment, up to the respectable height of 64 per cent for its parent industry. Apparently, inferentially and not surprisingly, the employees of machinery making firms - and not the population at large-devise the new machining tools and techniques. This last bit of evidence, a step toward the restoration of our hypothesis linking employees and their technology, however, leaves us unprepared for the next blow to fall. An aggregate of all metalmaking, metal working, and machining patents (ten classes) was correlated with the sum of the employments in the primary metal, fabricated metal, and nonelectrical machinery industries with the rationale that, if these various patent classes do in fact cut across industry boundaries to a serious degree, the ambiguity of the classifications and associations would be lessened. But the evidence is that all manufacturing employment (0.93) and total population (0.89) are more closely correlated with the ten-class aggregate than is true of an aggregate of direct employment in the three presumably related industry groups $(0.83)$. 
As some comfort, the advantage held by the two grosser measures is much less than an average (simple or weighted by patent or employment frequencies) of the coefficients of the component (three) sets of correlations. Still, the influence of the basic metal-primary metal industries relationship, wherein associated employment performed most poorly, was too strong to be fully offset by such improvements in process-product alignment as might have been achieved by using broader patent and industry classes. It seems that we must leave the metalmaking, metal working and machining patents with whatever consolation can be derived from the machining-machinery associations.

The attempt to link chemistry patents with related employment runs afoul of the same problem encountered in the metal working patents-fabricated metal industry correlation. Chemical employment is very highly correlated with manufacturing employment $(0.96)$ and population (0.97), making it difficult to separate the three potential determinants of chemistry patenting. Still, while chemical employment plays nip and tuck with population in the correlations with chemistry and plastics patents, maintaining only a slight edge over the latter, by judicious combination of chemical employment with employment in petroleum and coal products in one case (carbon compounds) and with rubber products employment in another case (plastics), parent industry employment achieves a narrow but recognizable margin of superiority over total population as the probable inventing population. Certainly, much more work must be done before any neat technical linkage of process and product can be expected in any of these patent class-industry group associations.

This attempt to establish close correspondence between patent classes and Census industry groups is not a pure mental exercise. If the employees of a given industry are the primary, or even a significant, source of that industry's technological change, then the construction of a satisfactory over-all index of local inventiveness must await the tabulation of patent frequencies by patent class and the classification of patent classes by industry group. The former is a routine job; the latter will surely prove to be a very difficult task. Of course, if invention is substantially independent of an individual's vocation or industry association, an industry-mix deffator is superfluous. But modest as the results have been, it would be hazardous to assume that research and invention is not importantly job oriented. And some index of the propensity to invent would seem to be a prerequisite to any incisive 
analysis of the locational pattern of inventive activity, or at least a prerequisite to empirical analysis of a high order.

\section{Technological and Industrial Complexes}

Correlation programs for automatic data processing equipment yield the coefficients for each variable with every other variable, indiscriminately. While often the extra coefficients are meaningless, occasionally valuable by-products are formed. In the course of correlating patent grants in various patent classes with employment in related industry groups, the correlation coefficients of the various patent frequencies with each other and employments with each other were automatically generated. These separate patent and employment matrices are reported in Table 4 in the hope that they may suggest additional avenues of inquiry.

TABLE 4

Coefficients of Correlation Between Patent Grants in Selected Patent Classes and Between Employments in the Industries Associated with the Patent Processes, by Standard Metropolitan Areas, 1947

\begin{tabular}{lccccc}
\hline \hline \multicolumn{5}{c}{ The Patent } & Matrix: \\
\multicolumn{1}{c}{ Pasic } & The Technological Complex & & \\
Metal & Turning & & \\
& Metal & Working & \& Cutting & Engines & Chemistry \\
\hline 7 basic metal processes & 1 & & & & \\
Metal working & .89 & 1 & & & \\
Turning and gear cutting & .72 & .82 & 1 & & \\
Internal-combustion engines & .58 & .74 & .64 & 1 & \\
Chemistry & .90 & .72 & .58 & .41 & 1 \\
\hline
\end{tabular}

The Employment Matrix: The Industrial Complex

Census Major Industry Group

\section{Prim. Fab.} Metal Metal Machinery
Trans.

Equip. Chemicals

\begin{tabular}{llllll}
\hline Primary metal industries & 1 & & & & \\
Fabricated metal products & .71 & 1 & & & \\
Machinery, exc. electrical & .60 & .90 & 1 & 1 & \\
Transportation equipment & .36 & .61 & .59 & 1 & 1 \\
Chemicals and allied prod. & .40 & .83 & .71 & .45 & 1 \\
\hline
\end{tabular}

SOURCE: see Table 3.

The first thought that comes to mind is that perhaps we may compare the general level of coefficients in the two matrices to determine whether the technological or the industrial complexes are tighter knit. That is to say; are the interindustry or the interprocess spatial ties the stronger? If our Table 4 does indeed accurately reflect agglo- 
merative forces, inventive activity evidences the greater spatial cohesion with a median correlation coefficient of 0.72 , as compared to a median of only 0.60 for employment. This is not to say that the various classes of inventive activity are more spatially concentrated than the various groups of industrial employment, only that geographic centers of one kind of inventive activity tend to a greater degree to be the centers of other kinds of inventiveness, than do production centers of one industry tend to be production centers of another industry. If this chain of thought has not yet strained fact or logic, these tentative conclusions suggest that inventive activity may be subject to external economies of scale (really economies of spatial agglomeration) that are more independent of a particular kind of process or product line than is true of production. (Or it may be that production entities more commonly repel each other, through labor market competition, for example.) But the base here is much too slim to support any more - perhaps even this much-deductive superstructure.

Attention is called to the fact that the two matrices present very similar patterns. Internal combustion engine patents as a class and its counterpart, transportation equipment employment, seem to stand aloof in technology and production with consistently low coefficients, whereas the class of metal working patents and its counterpart, fabricated metal products employment, seem to stand in the center of all activity with consistently high coefficients. Further, two of the tightest sets of spatial linkage are metalmaking patents with metal working patents with turning and gear cutting patents and their counterparts, primary metal employment with fabricated metal employment with nonelectrical machinery employment. These comprise very believable technological and industrial complexes.

One interesting divergence between the two matrices is the very high correlation $(0.90)$ between chemistry patents and the seven selected basic metal patents, in contrast to the very low correlation $(0.40)$ between chemical and primary metal employment. In fact, further study of the first column of the two matrices reveals that it is here that the patent matrix piles up its lead in spatial linkage over the employment matrix. If the first column were removed there would be little to choose between the two complexes-almost identical medians for the remaining six coefficients. The substance of this statement is that the primary metal industries have relatively isolated centers of production, while research and development in the basic metalmaking processes seems to be an integral part of industrial research in general. 


\section{The Scale Effect in Inventiveness}

I have been playing the part of a host who has dallied through the hors d'oeuvres because the entree is not ready to be served. Certainly, the piece de resistance of this study should be a determination of the extent and character of any economies or diseconomies of spatial agglomeration in invention that may exist. Simple, linear correlations do not, of course, shed much light on this matter; a linear correlation, in fact, presumes that scale effects do not exist in significant measure. But recourse to the underlying scatter diagrams may disclose nonlinearities in the patent-employment-population relationships.

Careful examination of the scatter diagrams, however, failed to reveal any impressive evidence of curvilinear relationships. Occasionally, by squinting and frowning heavily, a slight suggestion of concavity or convexity was apparent-more apparent than real, no doubt. The pattern of scatter was never so suggestive as to warrant the minor inconvenience to trying to fit some simple second degree function to the data. Nor were the " $y$ " axis (patent grants) intercepts of the simple regression lines significantly enough different from zero to indicate (linear) economies or diseconomies of very small size.

A priori, patent grants of any particular kind would seem to be a function of associated employment and of some more general population, with the former exhibiting a regression coefficient two or three or more times that of the latter. (That is, the expectation is that chemical workers contribute to chemical technology at a rate a couple of times as great as that which applies to other persons.) Some limited experiments with multivariate analysis were conducted but a much more comprehensive and sophisticated statistical treatment is indicated, bringing in population size, industrial structure, educational level and facilities, industrial maturity and other socioeconomic facets of the city region. In any event, multiple correlation and regression analysis seems to be a much more promising approach to the analysis of the location of inventiveness than further experimentation with indexes of local inventiveness. A prey as elusive as "inventiveness" calls for a very fine net. 


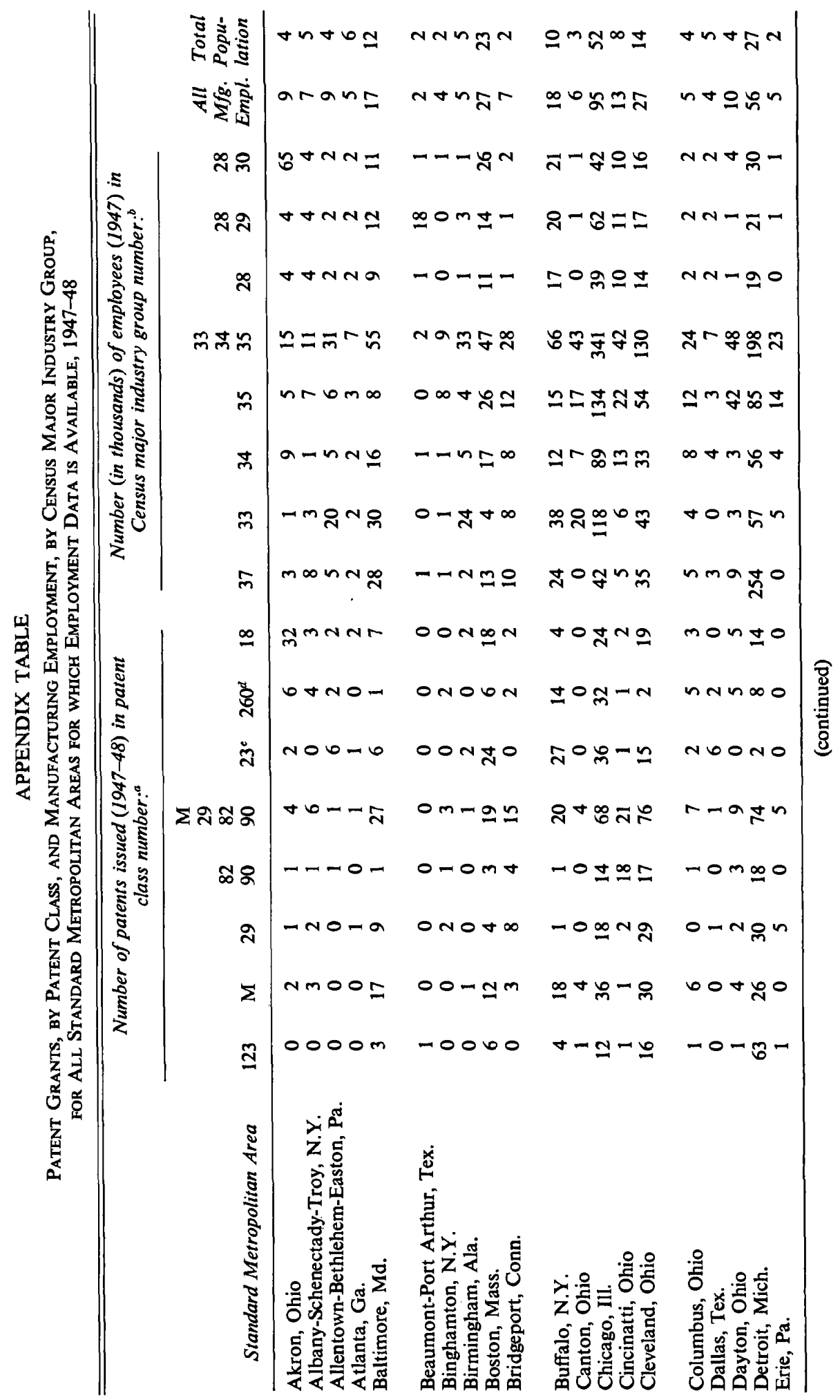




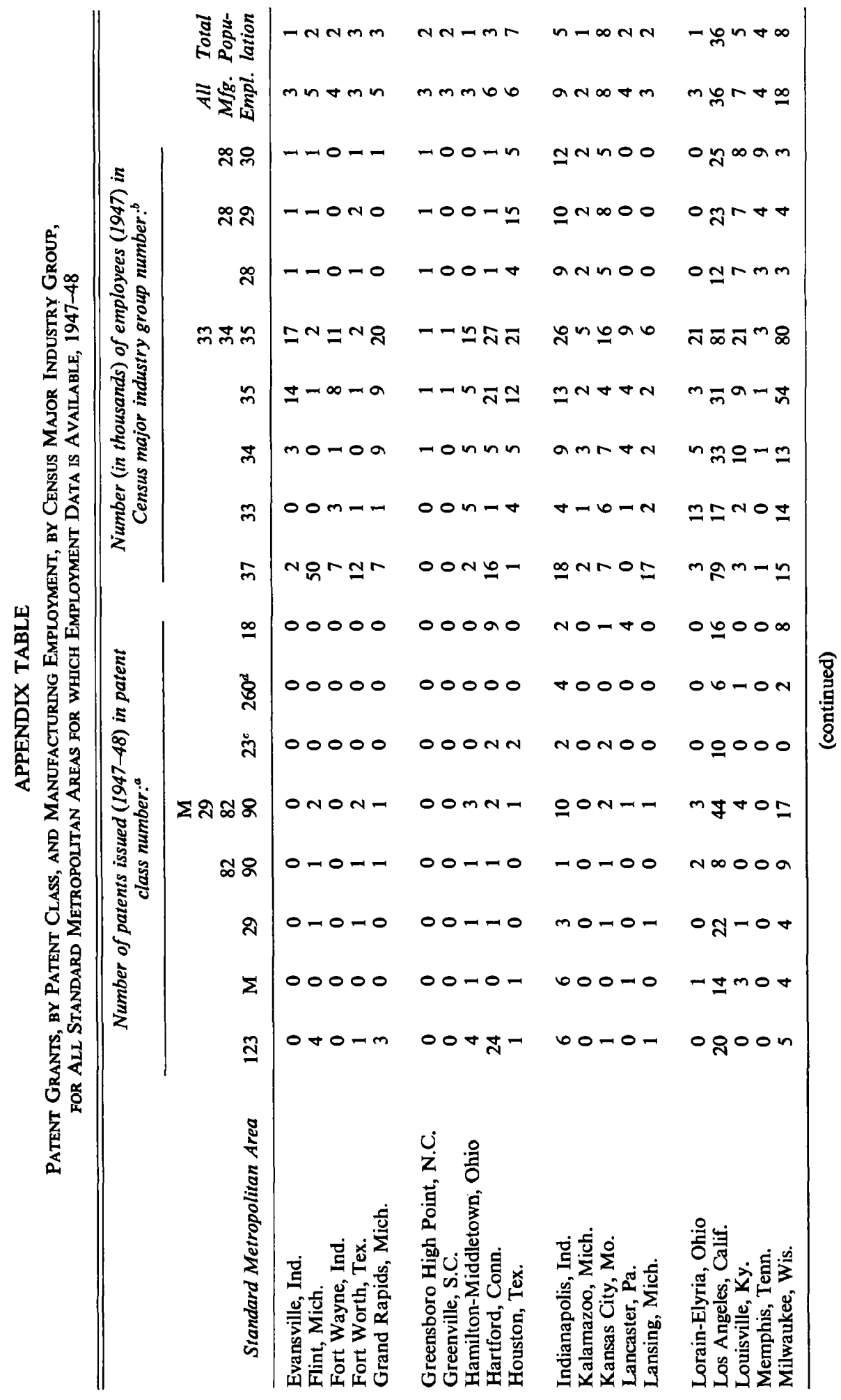




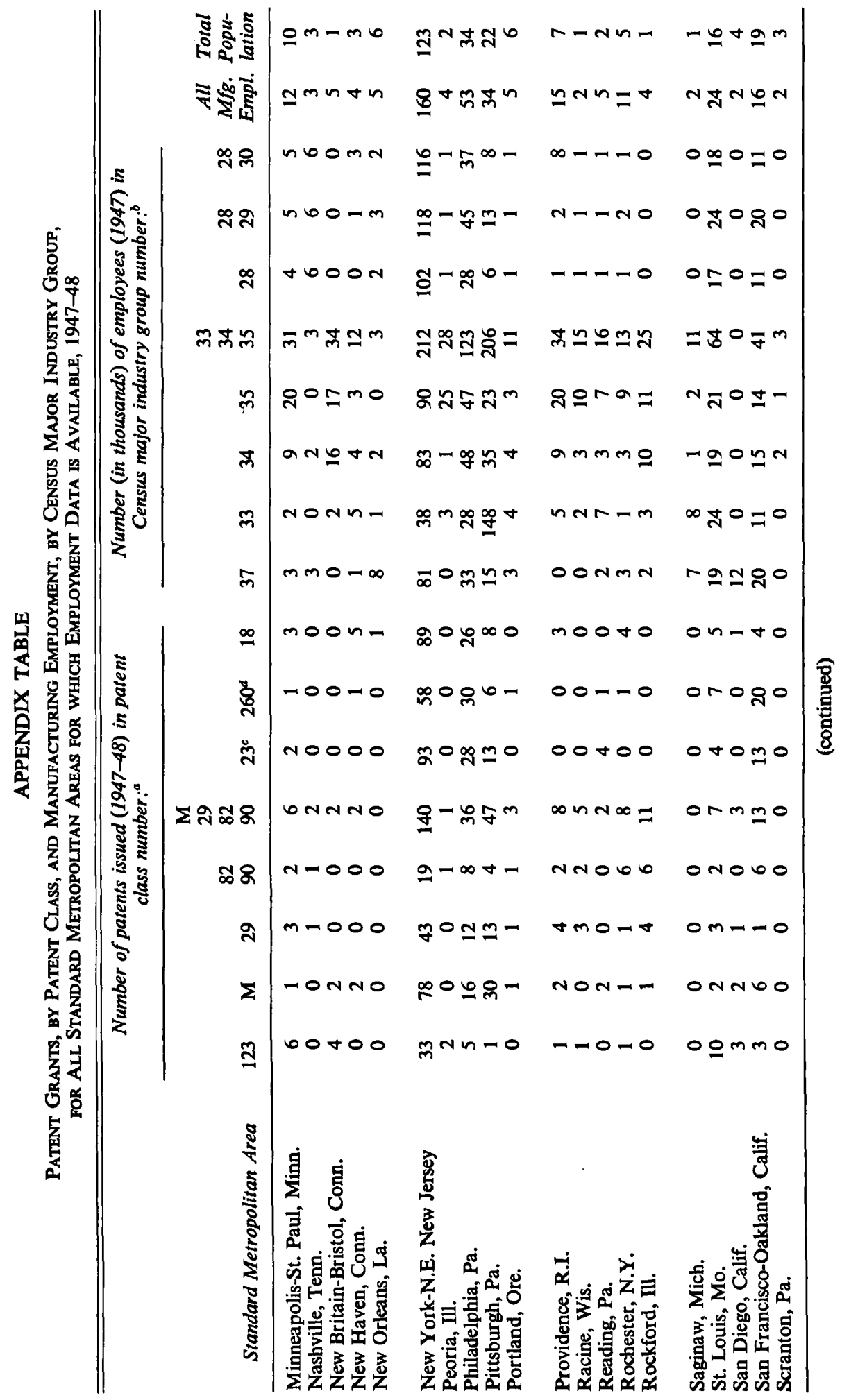




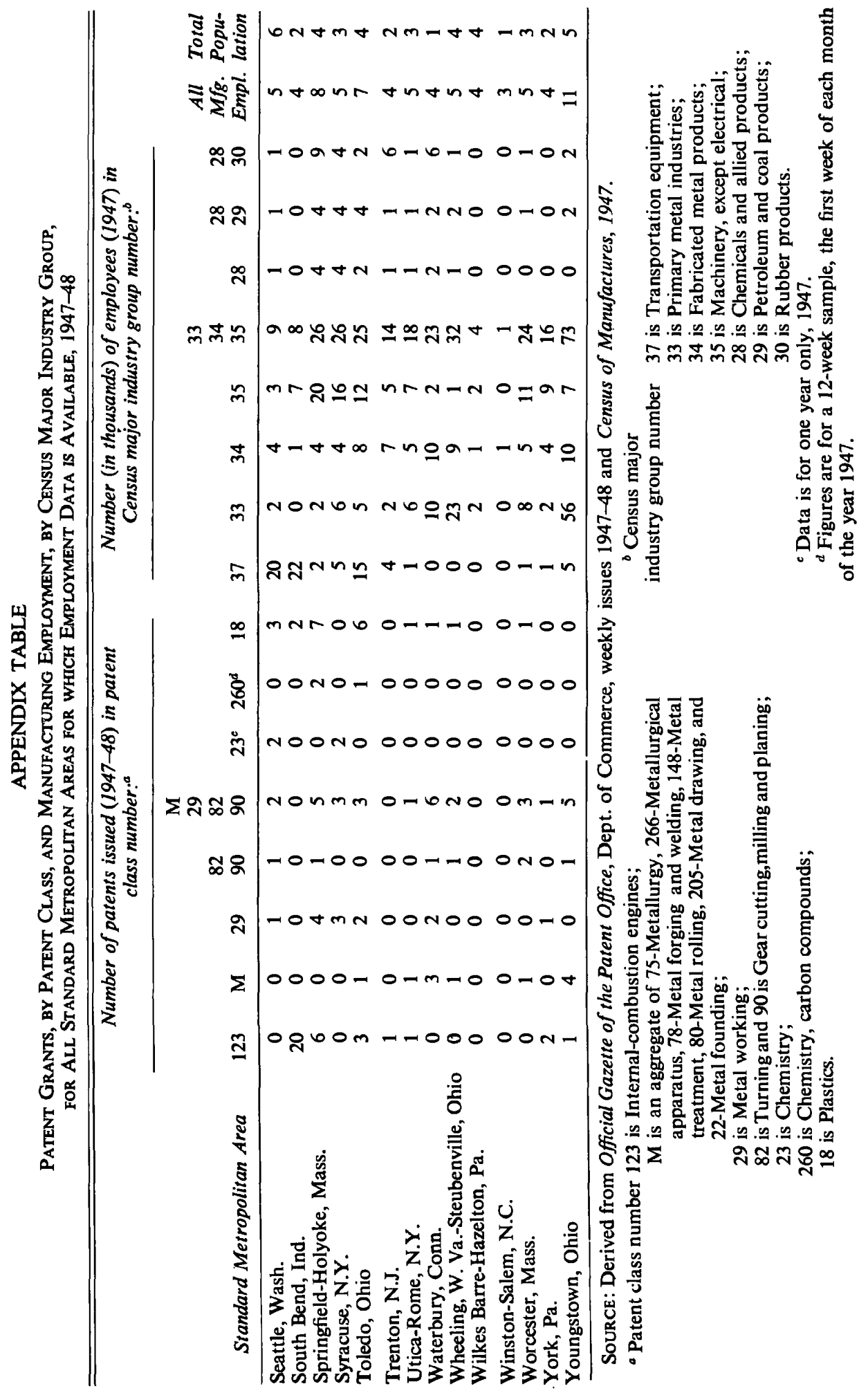


